\title{
Towards representative expert surveys: Legitimizing the collection of expert data ${ }^{1}$
}

\author{
Dr Dimitrios C Christopoulos \\ Bristol - University of the West of England, dc.christopoulos@uwe.ac.uk
}

\begin{abstract}
A consistent problem with key informant, elite and expert interviewing is the representativeness of sample populations. Since studies that employ such techniques depend on a small number of respondents, they are often classed as qualitative. The possibility of going beyond these classic approaches arises by employing methods developed to explore hidden populations in network analysis. These would qualify as descriptive quantitative techniques since we cannot provide a robust measure of reliability. It is the case however, particularly in the investigation of small populations of expert opinion, that we can be confident of surveying a sizable proportion of that population. A case study of such a survey employing Peer Esteem Snowballing (PEST) is offered in demonstration.
\end{abstract}

Keywords: expert surveys, network snowballing, informant surveys

\section{Why collect expert opinions?}

1.1 A number of expert professionals possess knowledge or can make assessments that are not available in the public domain. This knowledge is often considered confidential, sensitive or privileged. It could pertain to knowledge or assessment of illegal activities or the covert activity of powerful individuals or organizations. The appeal of the method is widespread with the United Nations Development Programme (UNDP, 2003:xi) listing twelve different longitudinal such surveys. ${ }^{2}$ Often the information sought is not inaccessible because a topic is sensitive but because public consensus has not been reached, the information is highly sophisticated or there is a requirement for exceptional expert judgment. Furthermore, social scientists are often faced with conceptual questions that can only be answered tentatively. How powerful is a state? How influential is a policy maker? How significant is a policy innovation? Answers to such questions cannot be given by public opinion surveys as it is impossible to control for inherent biases in public opinion related to media interest or the sophistication of the domain in question. Social scientists, more often than not, resort to interpretative methodological tools or critical analysis to provide a substitute for the dearth of reliable data (Hay, 2002).

1.2 If informed opinion is deemed relevant for answering such questions we are faced with the issue of defining who are those that can legitimately be considered as experts. ${ }^{3}$ In other words, we have to find a valid method for correctly identifying the population and then defining its boundaries. Ideally we would end-up surveying a sample of these experts. Most important issues to be tackled are:

a. who is authoritative enough to provide such opinion,

b. how big is the population of experts,

c. can we define population boundaries,

d. how are we going to access these experts,

e. how are we going to get a high response rate from them,

1. As presented in the Eurostat Conference for New Techniques and Technologies for Statistics, under the title 'Peer Esteem Snowballing: A methodology for expert surveys', Brussels, February 2009, also available in the Conference Proceedings. pp171-179.

2 . Kaufmann et al (2005) comparing a great number of available expert indexes claim that ideological biases of experts seem to have little effect on their assessments.

3 . This can be linked with identifying key actors through reputation. 
f. how to measure and interpret biases in non-response and

g. how to effectively administer the interviews/ surveys in a time frame that will not diminish their validity.

1.3 The methodological insights afforded through network analysis (Wasserman and Faust, 1994; Carrington, Scott and Wasserman, 2005) combined with classic snowball sampling techniques (Goodman, 1961) and elite survey method insights (Berry, 2002; Dorussen et al, 2005, Lilleker, 2003; Aberbach and Rockman, 2002) ${ }^{4}$ permit the adjustment of snowballing techniques in order to construct pseudo-representative samples of experts. Instrumental in this process is developing the insights of the seminal paper by Frank and Snijders (1994) who have looked at ways of estimating network size (population) through a snowball sample. ${ }^{5}$ Furthermore, by combining elements of probability sampling for informants, as explored in Marsden (2005) and probabilistic network sampling as explored in Frank (2005) we can address issues related to defining the boundaries of an expert population.

\section{A novel pestering tool}

2.1 I have devised a new tool that allows for a combination of network analysis into snowballing of expert informants. I call this tool PEST for PeerEsteem Snowball Technique. The tool improves on both classic and probability snowball samples by:

1. taking account of network boundaries,

2. reducing selection bias,

3. providing an estimate of population size and

4. allowing for clustering of expert opinions on the basis of their nomination network.

2.2 I use a case study to demonstrate how the technique can provide reliable measures of expert opinion premised on estimates of population size and divergence of expert opinion. Network graphics provide a visual representation of the different waves of snowball nominations and a cluster analysis of expert nominations can provide an indication of any sub-clustering for the reputation of expertise.

2.3 PEST expands on classic snowballing techniques by seeking multiple gatekeeper access points on what can be small but not always visible populations of experts. The selection of multiple 'entry' points, objectively selected, attempts to deal with some of the problems identified by Erickson (1979) as fundamental weaknesses of snowball sampling. These weaknesses are related to selection bias, population clustering and the difficulty in motivating expert participants. ${ }^{7}$ The intellectual debt of the technique lies with Goodman (1961) who proposed that a snowball sample can reveal a population through a chain of nominations and re-nominations. He considered those contacted first to constitute a 'first order' zone of the network that will then nominate those that become the 'second order' zone and so on in a chain method that will reveal a complete network component.

2.4 Heckathorn (2002) offers a statistical probability proof that, within three to four waves, most heterogeneous populations snowball sampled through random seeds will elicit a sample with characteristics representative of the target population. He provides some evidence that respondent driven sampling has less bias and suggests that recruitment in snowballs are in effect 'memory-less' and can therefore lead to a representative sample. His first theorem states that "as the recruitment process continues from wave to wave, an equilibrium mix of recruits will eventually be attained that is independent of the characteristics of the subject or set of subjects from which recruitment began" (Heckathorn, 2002:16). However, as Heckathorn (2002:23) concedes his method can be biased for groups with unequal size of population $N$.

2.5 There are two fundamental stages to PEST that marginally vary from classic snowballing. First is to objectively identify a number of informants that should provide unbiased initial nominations. And second to

4. See Burton and Higley (1987) for a critical examination of elite theory concepts.

5 . Frank (2004) has also employed snowball sampling to estimate the social capital of a population.

6 . This instruments' potency as a pestering tool will determine whether it deserves this presumptuous title.

7. These can also be related to more traditional concerns of response rates in surveys (Yanmarino et al, 1991). 
employ these nominations and generate further nominations in a series of snowball 'waves' that allow determining the size of the 'hidden' population. A comparison of the technique with other snowball sampling methods is presented in Table 1.

\section{Expert surveys, key informant methodology and network analysis}

3.1 Expert surveys typically borrow tools from key informant methodology which is often assumed to allow insights with higher validity than large scale surveys. Deux and Callaghan claim that "the use of the key informant approach ensures less bias and distortion than a random-digit-dialed telephone survey of individuals who are asked to report on their own behavior" (1984:490). Kumar, Stern and Anderson (1993) though, identify a fundamental problem with expert surveys. Namely, the aggregation of responses. Since classic snowball studies incorporate no reliable information on the size of the population of experts, averaging responses is a crude method that decreases construct validity. Dorussen et al (2005) deal with a similar aspect of the same problem by allowing for heterogeneous level of competence among respondents. The assumption there is that experts are more likely to be right about issues in which they have 'specific' expertise.

3.2 Accessing and achieving high response rates among key informants depends on traditional survey techniques in response induction. These consist of employing reminders through mail, e-mail or phone calls. It is claimed that "an informant's decision to respond to an organizational survey involves a consideration of three general processes: authority, capacity and motivation" (Gupta et al, 2000:327). The researcher is required to play at what can be a very delicate balancing game between an informant's personal and organizational characteristics. Engaging in this process the researcher increases the probability of selection bias. It has also been suggested that "response probability mirrors differences between samples in (a) the extensiveness of preparatory work and (b) the centrality of the research question to informants" (Yanmarino et al, 2000:343). Again, evaluating how much preparatory work is adequate for respondents to be motivated as well as estimating the degree to which responses are affected by central research questions create further potential for response bias. Such bias may be of small significance in large scale surveys but could seriously prejudice instruments aimed at small groups of elite or expert actors.

3.3 Social network analysis on the other hand, has developed a wide variety of methods for the study of small closely knit populations. Groups of experts neatly fall within such conceptualisation. Rothenberg (1995) in an overview of sampling claims that, in network analysis, targeted sampling is critically dependent on defining the sample area, estimating the population and recruiting participants. ${ }^{8}$ Targeted snowball sampling allows us to fulfill all those criteria. It is not claimed that this is a random sample that would meet the Bernulli criteria for randomness of selection. Sampling here should rather be seen as an ascending method of data gathering which is distinct from classic probability samples. "The fundamental difference between the two approaches is that the descending method chooses a sample; the ascending method constructs a population" (Rothenberg, 1995:107). It is in this process of constructing a population that snowball sampling can improve the reliability of data on expert surveys. A caution should be offered here in that snowball sampling "seems less suited for the study of relationships containing a large number of weak ties" (Johnson et al 1989:156). To the degree that expert nominations can be considered weak ties then network analysis may not be the best tool in estimating clusters of experts. Although reputation can be perceived as a weak tie within a professional environment it is also the most fundamental intangible that actors possess. They would therefore be well aware of the existence of such an asset among their peers.

3.4 I have previously (Christopoulos, 2007) compared the basic parameters of the three different snowball techniques. Classic and purposive snowball sampling (a), with probability and respondent driven snowball (b), compared with PEST (c). The latter is constructed by estimating the population size employing the Frank and Snijders (1994) algorithm (explained below). The technique is based on attaining a sample of actors to provide referrals for others and subsequently estimate the overlap of these referrals. In the context of expert surveys this is the reputation of others as experts. The initial 'seeds' or 'entry points' is attained by combining a gate-keeper

8 . Kogovsek and Ferigoj (2005) examining a range of data collection instruments for network analysis find telephone surveying to provide the most reliable measurements of egocentred ties. Jackson et al (2005) provide a review of methodologies for collecting data from subpopulations. 
with a random seed process. During the first wave, nominations are requested from the initial pool of seeds. After estimating the network size we proceed to further waves until we attain a sample size that would allow us a claim to pseudo-representativeness. ${ }^{9}$

\section{A case study: Sampling experts on the power of EU regions}

4.1 In a case study conducted between March and December 2005 a good number of key informants were asked to nominate field experts. Informants were chosen following a review of the current literature on a number of key academic journals. Twelve (12) authors published in the field of regional politics of Poland, Spain and the UK were approached in March 2005. This first approach for nominations was also accompanied by a copy of the survey tool with a request for feedback. The analysis of responses provided the background to a paper (Christopoulos, 2007) that allowed a critical evaluation of both the technique and the hypotheses.

\section{Table 1: Generic stages for PEST}

\begin{tabular}{|l|l|l|l|l|}
\hline & 1st Stage & 2nd Stage & Subsequent Stages & Final Stage \\
\hline Primary Scope & $\begin{array}{l}\text { Selection of seed } \\
\text { nominators }\end{array}$ & $\begin{array}{l}\text { Approach first wave } \\
\text { nominees }\end{array}$ & $\begin{array}{l}\text { Approach all new } \\
\text { nominations and non- } \\
\text { respondents }\end{array}$ & $\begin{array}{l}\text { Reach population } \\
\text { saturation or } \\
\text { significant sample } \\
\text { size }\end{array}$ \\
\hline $\begin{array}{l}\text { Validity } \\
\text { Expiderations in }\end{array}$ & $\begin{array}{l}\text { Estimate the degree of } \\
\text { fragmentation of the } \\
\text { population. } \\
\text { Include all subclusters of } \\
\text { experts. }\end{array}$ & $\begin{array}{l}\text { Non-response bias. } \\
\text { Authority of sponsoring } \\
\text { organization affects } \\
\text { non-response. } \\
\text { Centrality of nominated } \\
\text { actors. }\end{array}$ & $\begin{array}{l}\text { Approach to non- } \\
\text { respondents. }\end{array}$ & $\begin{array}{l}\text { Unlikely to reach } \\
\text { saturation. } \\
\text { Sampling may not } \\
\text { sufficiently capture } \\
\text { diversity of views. } \\
\text { Not a good } \\
\text { instrument for } \\
\text { capturing scientific } \\
\text { dissent. }\end{array}$ \\
\hline
\end{tabular}

4.2 The first wave of the survey was sent to all nominated experts on October $15^{\text {th }} 2005$. This resulted in a number of further nominations. The second wave was disseminated on November $10^{\text {th }} 2005$. Thirty five (35) experts in total were contacted seven of which were approached twice since they had not returned a completed questionnaire by the time of the second wave. By the cut-off date of December $10^{\text {th }}$ there were 20 responses. Fifteen of the questionnaires were sufficiently complete to be employed in the final analysis. By the end of what are in effect three waves of nominations (seed nomination and two survey waves) there have been 56 experts nominated, 16 of which had multiple nominations. Nominee home institutions were in Poland (24), Spain (18), the UK (8), Italy (4), the US (1) and Belgium (1). Nominators are based in academic or research institutions in Poland (5), Spain (4), the UK (4) and Italy (2), while five respondents did not make nominations. All correspondence was conducted by e-mail. Respondents' institutional base does not always signify national expertise, while most respondents pronounced expertise in the regional politics of more than one country.

\section{Table 2: Nomination wave statistics for case study of experts}

\begin{tabular}{|c|c|c|c|c|c|c|c|}
\hline \multirow{2}{*}{$\begin{array}{l}\text { Estimators of } \\
\text { sample and } \\
\text { population size }\end{array}$} & \multicolumn{2}{|l|}{$1^{\text {st }}$ Stage } & \multicolumn{2}{|l|}{$2^{\text {nd }}$ Stage } & \multicolumn{2}{|c|}{ Subsequent Stages } & \multirow{2}{*}{$\begin{array}{l}\text { Final Stage } \\
\text { Estimated population } \\
\text { size }^{3}\end{array}$} \\
\hline & \multicolumn{2}{|c|}{$\begin{array}{l}\text { Minimum number of entry } \\
\text { points to snowball } \\
\qquad n \geq 4.47\end{array}$} & & & & & \\
\hline $\begin{array}{l}\text { Actual number of } \\
\text { experts surveyed } \\
\text { and nominated }\end{array}$ & $\begin{array}{l}\text { Approached } \\
\text { for } \\
\text { nominations }\end{array}$ & $\begin{array}{c}\text { Initial } \\
\text { nominators }\end{array}$ & $\begin{array}{c}\text { First } \\
\text { Wave } \\
\text { Surveyed }\end{array}$ & $\begin{array}{c}\text { Response } \\
\quad(+2 \\
\text { incomplete })\end{array}$ & $\begin{array}{l}\text { Second } \\
\text { wave } \\
\text { (+7 sent } \\
\text { reminder) }\end{array}$ & $\begin{array}{c}\text { Response } \\
\quad(+3 \\
\text { incomplete) }\end{array}$ & $\begin{array}{c}\text { Experts Responded to } \\
\text { Survey }{ }^{4} \\
20 \\
\text { completed survey }\end{array}$ \\
\hline & 12 & 4 & 15 & 8 & $20^{2}$ & 7 & 15 \\
\hline
\end{tabular}

9. There are widespread algorithms that calculate an optimal sample size given a confidence interval level, a confidence level and a proportion of acceptable error. They are of little use in snowball sampling as they assume random selection of the sample and a normally distributed chance of such a selection. 
Notes: 1. Calculated ex post facto employing the formula provided in Frank and Snijders (1994) and assuming that the network centralization of the sample is representative. The average outdegree indicating number of nominations is 2.7. 2. The minimum inference in qualitative research discussed in King, Keohane and Verba (1994) is for $n$ to lie between five and twenty observations $(5 \leq n \leq 20)$. 3. Estimate based on Frank and Snijders (1994). 4. Twenty respondents in total, five of which are eliminated from the final analysis due to incomplete responses.

4.3 In total 35 experts were approached and 56 nominations were received. Applying the Frank and Snijders (1994) estimator we generate an estimate the population size to be 58 people (see table 3 below) implying a sampling rate of $34 \%$. Valuable surveys are provided from $26 \%$ of that population. Nominations are obviously not independent events. However this is a large enough section of the population of experts to provide us with confidence that views expressed are to a fair degree representative. Indeed it can be argued that snowball samples should report this population estimate as a pseudo-robustness indicator as we cannot at this stage provide statistics for confidence levels.

\section{Interpreting the case study results}

5.1 A network analysis of nominations reveals strong country based clusters. This is particularly the case in Poland and Spain where the nominations are almost exclusively within national boundaries. ${ }^{10}$ My analysis of respondent nominations in figure 1 provides evidence of the existence of strong clusters. Very few experts appear prepared to nominate an alter located in a different country.

Figure 1: Network analysis of nominations employing the factions routine in Netdraw

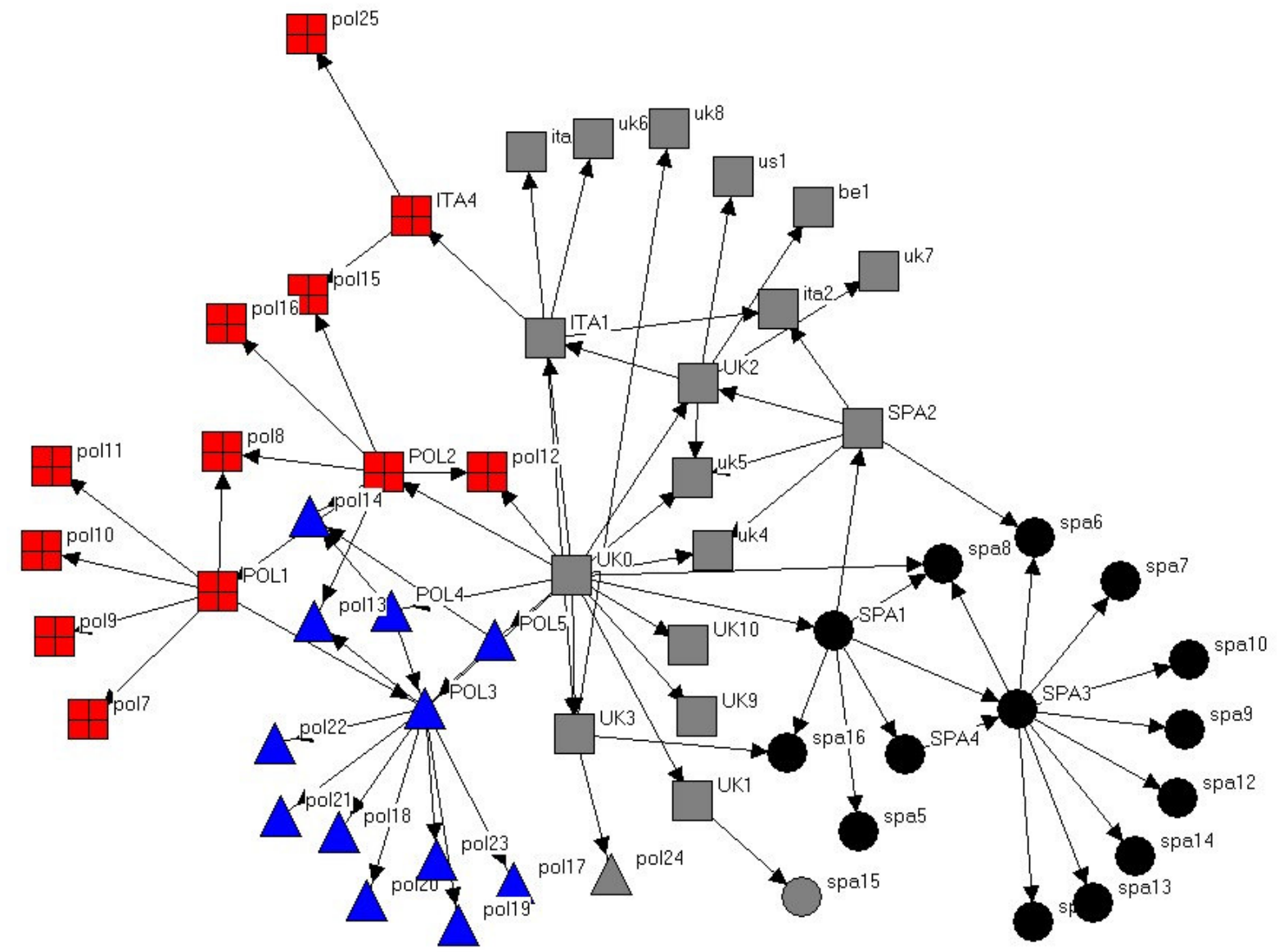

Note: Four factions are identified by colour. Minor presentational alteration of the shape of actors spa15 and pol24 to allocate them to their respective national factions. (Borgatti et al, 2002)

10. This result was somewhat surprising as I was expecting a high number of nominations for prominent authors and researchers that would not correlate with the national basis of the nominators. However, as I was attempting to investigate a very specific set of research questions, respondents may have interpreted nominations to be targeted at those they considered instrumental in the specific territorial context. 
5.2 It has been suggested that the characteristics of hidden populations can be sufficiently explored with between three to four waves of snowballing. The technique developed by Heckathorn (2002) employs responded driven sampling to develop pseudo-probabilistic sample surveys. That methodology is premised on the assumption that respondents would be prepared to divulge information that would allow for a reliable estimation of their network size, the size of their sub-group and the proportion of their brokering ties. In the context of expert surveys however, respondent driven sampling would most likely negatively affect response rates and is likely to lead to a deterioration of data quality. The information required from actors is not directly related to their networks but to the reputation of others.

5.3 A sociometric analysis reveals very few reciprocated nominations. If the initial nominations (first wave) is excluded there are four main subclusters of nominations and three components (excluding isolates). One component consists of the Polish nominations and is subdivided into two clusters. While the other main component is subdivided into the Spanish and British clusters. The lack of bridges in nominations indicates that there are 'entrepreneurial' opportunities for individuals that will be prepared to bridge the structural holes present (Burt, 1992). This should be seen as scope for cross-fertilisation of academics, between the academic communities of Spain Poland and the UK.

\section{Figure 2: Network visualisation by wave}

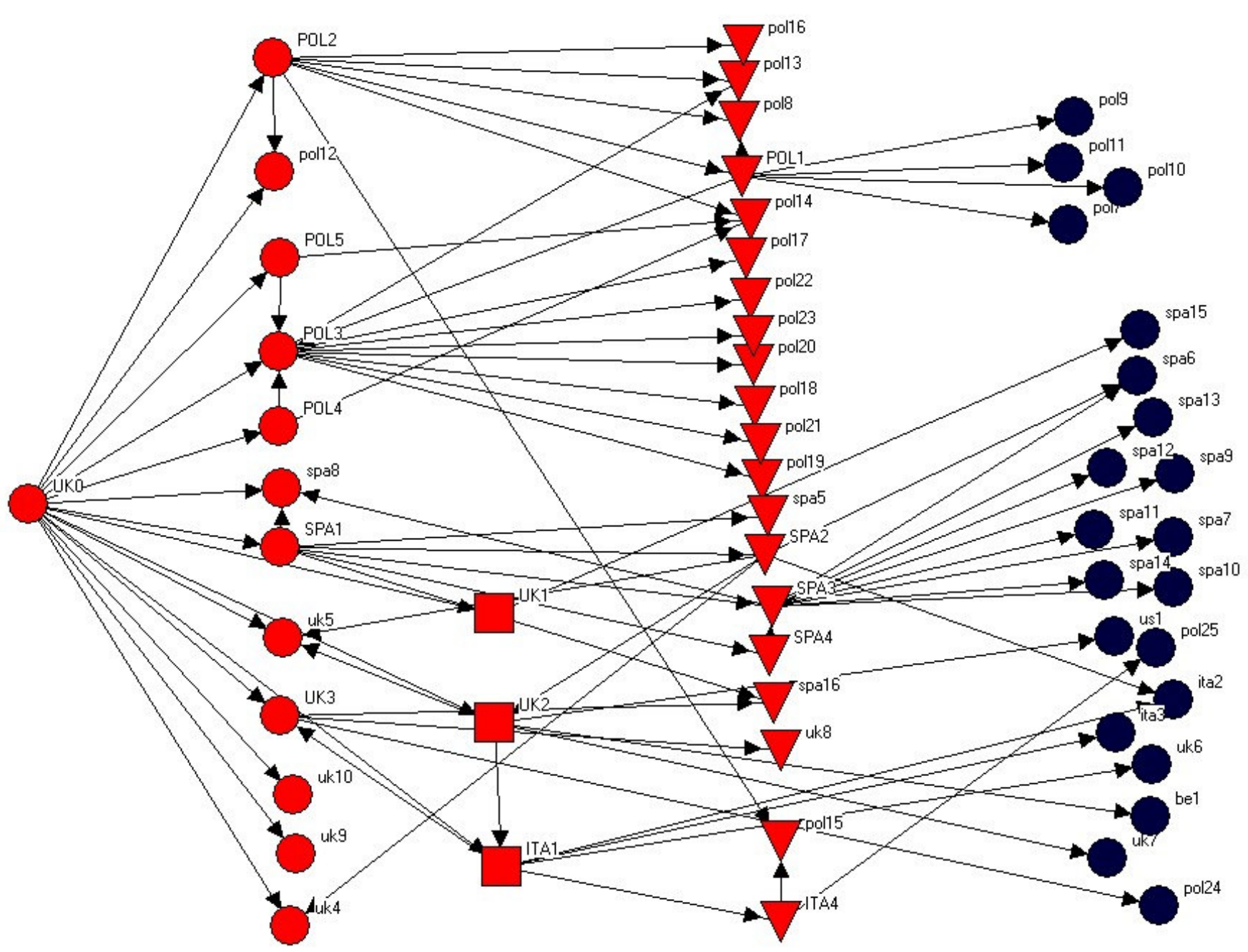

Note: UK0 aggregates the four sources for the initial 15 nominations (square are those that responded by the second wave). The 20 further nominations (triangles) are followed by the 21 last nominations (black circles). 
5.4 Table 3 has an abbreviated version of the output from running the algorithm developed by Frank and Snijders (1994). The estimations calculate the size of a hidden population based on the degree of overlap between two waves. Estimates here for the two more robust models v_ 3 and v_ 5 are of 82 and 58 members respectively. If v_3 and v_ 5 diverge, the latter is deemed more robust. ${ }^{11}$ This presents us with a good estimate of the population size and one that can be employed to estimate pseudo-representativeness for the sample employed. ${ }^{12}$

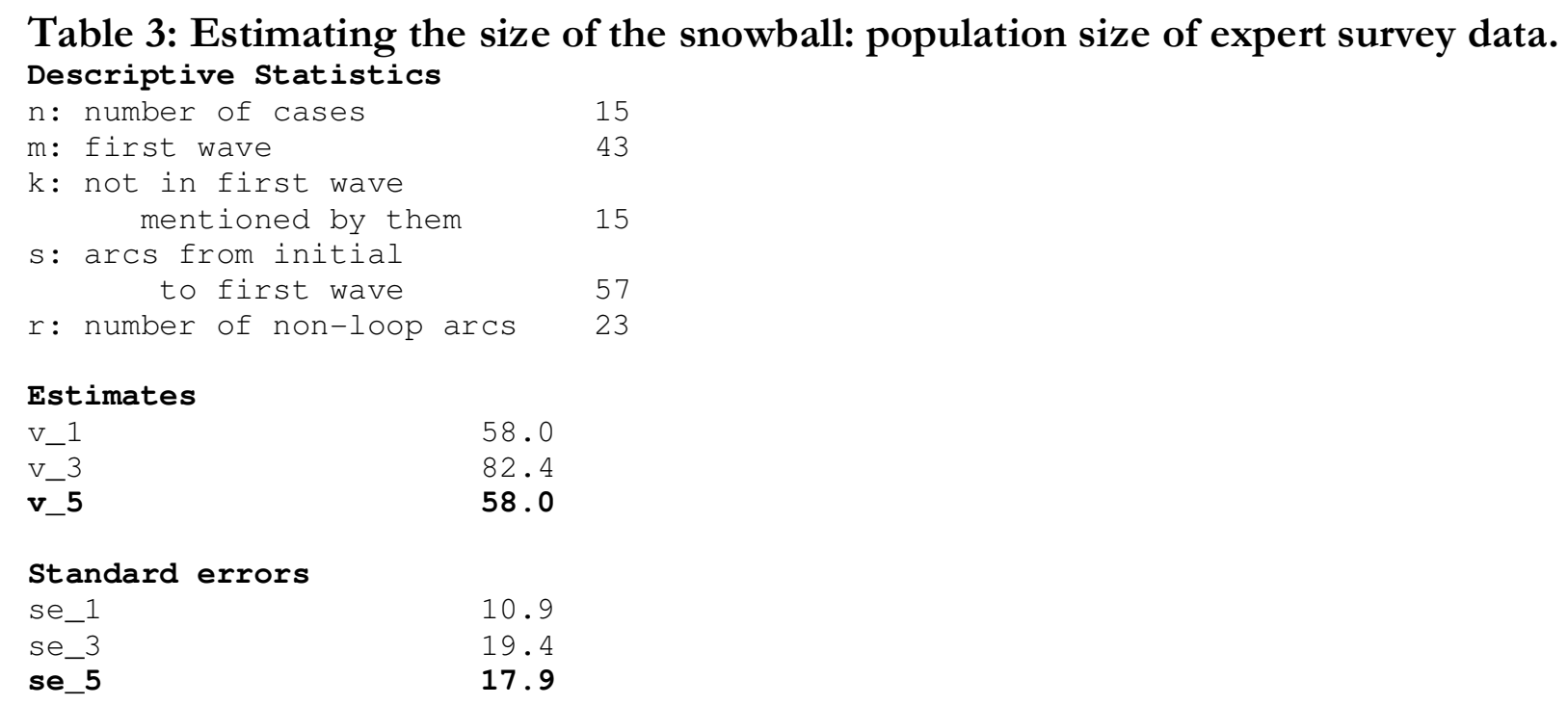

Note: Method as developed in Frank and Snijders (1994) estimates employing the dedicated snowball software. The authors favor estimates $v \_3$ and $v \_5$, but note that $v \_3$ may be biased. If $v \_3$ and $v \_5$ yield very different outcomes, they consider v_ 3 not to be reliable.

\section{Advantages of employing PEST}

6.1 The defining characteristics of PEST are compared to other snowballing techniques in Table 1. Significantly PEST:

a. reduces the selection bias inherent in initial seed samples for a snowball by advocating for a nominations phase that objectively identifies contact seeds for the first wave;

b. by analysing network data it provides an estimate of the population size, unbiased by any researcher defined population boundary;

c. by reporting the estimate of the sample size vis a vis the population, it provides a measure of relative significance (optimal sampling data can be reported in this context);

d. through a network analysis of referrals it allows for identifying clusters of experts that may be instrumental in explain variations in their response profile;

e. allows for a referrals nominations strategy that, in certain cases, could improve response rates, while

f. the nominations strategy acts as an ultimate validation of expertise for informants and therefore improves content validity.

6.2 PEST is more flexible than other snowballing techniques and allows for the inclusion of a number of further improvements on the standard snowball approach. Techniques that could improve the validity of PEST but have not been examined in the present context would include: (a) weighting responses, i.e. provide a weighting on the basis of the number of nominations per expert; and (b) devising of a threshold system, i.e. consider as

11. Within two standard deviations (a 95\% confidence interval) the upper and lower bound of v_5 would be 22 and 94 members to this network.

12 . Borgatti et al (2005) examine measurement error for random graphs and find that small non-systematic errors have very predictable effects on some measures of network structure. Their simulations indicate that "accuracy not only declines with increasing error, but does so predictably and monotonically" (2005:134). 
experts only those attaining a pre-set number of referrals. Similarly, it seems legitimate to assume that a nominations referral strategy in expert and informant surveys would reflect on improved response rates.

6.3 It can also be argued that an instrument employing a technique that objectively identifies seed nominations, simultaneously provides a good probability of sampling less visible sub-groups of experts. Furthermore, the elimination of bias in identifying 'elite' experts through their position or reputation further increases validity and our confidence in expert opinions surveyed. This work assumes that experts do not exist in isolation. Experts that do not enjoy the esteem of their epistemic community will not be included in the sample population. ${ }^{13}$

6.4 Concluding, a couple of points have to be raised on further research on small sample expert opinion analysis. Robustness on the snowball estimates could be improved by the incorporation of a measure estimating the effect of response rates. Statistics on a multi-wave snowball would also be beneficial. Although not strictly a representative or random sample, levels of confidence could be devised for snowballing by sampling high proportions of a target population. Finally, specifying a decision rule for treating outliers and aggregating responses among experts should improve overall validity of this methodology. ${ }^{14}$

\section{REFERENCES}

Aberbach, J.D., Rockman, B.A. (2002) 'Conducting and Coding Elite Interviews' in Political Science and Politics, vol.35 pp. 673-676.

Berry, J.M. (2002) 'Validity and Reliability Issues in Elite Interviewing' Political Science and Politics, vol.35, pp. 67982.

Borgatti, S., Everett, M. and Freeman, L. (2002) Ucinet for Windows: Software for Social Network. Analysis. Harvard, MA: Analytic Technologies.

Borgatti, S. Carley, K., Krackhardt, D. (2005) 'On the robustness of centrality measures under conditions of imperfect data’ Social Networks, vol.28, pp124-136.

Burt, R. (1992) Structural Holes: The Social Structure of Competition. Harvard University Press.

Burton, M. and Higley, J.(1987) "Invitation to Elite Theory: The Basic Contentions Reconsidered" in Power Elites and Organizations ed. by G. William Domhoff and Thomas R. Dye. Newbury Park-California: Sage Publications.

Carrington, P.J., Scott, J., Wasserman, S. (2005) Models and Methods in Social Network Analysis. Cambridge University Press.

Christopoulos, D. (2007) 'Peer Esteem Snowballing: A methodology for expert surveys', INSNA 29 ${ }^{\text {th }}$ annual conference, Corfu, May 2007.

Coleman, J.S. (1958) 'Relational Analysis: The Study of Social Organization with Survey Methods' Human Organization, vol.16, pp. 28-36.

Deux, E., Callaghan, J. (1984) 'Estimating Statewise health risk behaviour' in Evaluation Review vol. 8, pp467-92.

Dorussen, H., Lenz, H., Blavoukos, S. (2005) 'Assessing the Reliability and Validity of Expert Interviews' European Union Politics vol.6 pp315-37.

Erickson, B. H. (1979) 'Some Problems of inference from chain data' Sociological Methodology vol 10, pp276-02.

Fleisher, Mark S. (2005) 'Fieldwork research and social network analysis: Different methods creating complementary perspectives' Journal of Contemporary Criminal Justice vol 21, n.2, pp.120-34.

Frank, O. and Snijders, T. (1994) 'Estimating the size of hidden populations using snowball sampling'. Journal of Official Statistics vol 10, pp. 53-67.

Frank, O. (2004) 'Measuring Social Capital by network capacity indices'. In Flap, H. and Volker B. (eds.) Creation and Returns of Social Capital. London: Routledge.

13 . Most epistemic community work (Sabatier, 1998) makes intuitive or qualitative assessments of the size of the relevant population of experts.

14 . Dorussen et al by diversifying between leading and 'lay' experts have tested for variations and have found that "whether the leading expert is included or not does not make a large difference to expert agreement" (2005:318). So, agreement among experts is not necessarily a result of more authoritative knowledge. Statistics employed by the World Bank indices on governance (Kaufmann et al, 2004) provide a good justification for aggregation methods. They employ econometric analysis to aggregate a good number of indicators across time in order to attain significance in the observed change between time periods examined. 
Frank, O. (2005) 'Network Sampling and Model Fitting' in P. Carrington, J. Scott, S. Wasserman (eds) Models and Methods in Social Network Analysis. Cambridge University Press.

Goodman, L.A. (1961) 'Snowball Sampling'. Annals of Mathematical Statistics. Vol. 20, pp. 572-579.

Gupta, N., Shaw, J., Delery, J.E. (2000) 'Correlates of response outcomes among organizational key informants' in Organizational Research Methods, vol3, n.3, Oct 2000.

Hay, C. (2002) Political Analysis: A Critical Introduction. Basingstoke: MacMillan.

Heckathorn, D. D. (2002) 'Respondent Driven Sampling II: Deriving Valid Population Estimates from ChainReferral Samples of Hidden Populations' Social Problems, vol 49 n1 pp11-34.

Jackson, D., Kirkland, J., Jackson, B., Bimler, D. (2005) 'Social Network Analysis and Estimating the Size of Hard-to-Count Subpopulations' Connections, vol.26, pp. 49-60.

Johnson, J.C., Boster, J.S., Holbert, D. (1989) 'Estimating relational attributes from snowball samples through simulation in social networks', Social Networks vol. 11, pp 135-58.

Kaufmann, D. Kraay, A., Mastruzzi, M. (2005) 'Measuring Governance Using Cross-Country Perceptions Data' The World Bank, Washigton, DC.

King, G., Keohane, R.O., Verba, S. (1994) Designing Social Inquiry: Scientific Inference in Qualitative Research. Princeton University Press.

Kosgotvsek, T. and Ferigoj, A. (2005) 'Effects of reliability and validity of egocentered network measurements' in Social Networks, vol 27, pp205-29.

Kumar, N., Stern, L., Andreson, J. (1993) 'Conducting interorganizational research using key informants' in Academy of Management Journal, vol. 36, pp1633-1651.

Lilleker, D.G. (2003) 'Interviewing the Political Elite: Navigating a Potential Minefield' Politics, vol.23, pp207-14.

Marsden, P. (2005) 'Recent Developments in Network Measurement' in P. Carrington, J. Scott, S. Wasserman (eds) Models and Methods in Social Network. Analysis. Cambridge University Press.

Munck, G.L., Verkuilen, J. (2002) 'Conceptualizing and Measuring Democracy: Evaluating Alternative Indices' in Comparative Political Studies, vol. 35, n1. pp5-34.

Rothenberg, R. B. (1995) 'Commentary: Sampling in Social Networks' Connections vol18, pp104-110.

Sabatier, P. (1998) 'The advocacy coalition framework: revisions and relevance for Europe' Journal of European Public Policy vol. 5 p. 98-130.

Snijders, T.A.B. (2005) 'Models for Longitudinal Network Data' in P. Carrington, J. Scott, S. Wasserman (eds) Models and Methods in Social Network Analysis. Cambridge University Press.

UNDP (2003) 'Sources for Democratic Governance Indicators' Staff Publication, United Nations Development Programme, Oslo, Norway.

Watters, J.K., and Biernacki, P. (1989). "Targeted sampling: Options for the study of hidden populations". Social Problems 36(4):416-30.

Wasserman, S. and Faust, K. (1994) Social Network. Analysis: Methods and Applications. Cambridge University Press.

Yanmarino, F. Skinner, S. Childers, T. (1991) 'Understanding mail survey response behaviour: A meta analysis' in Public Opinion Quarterly, vol 55, pp613-39.

\section{Specialist Software}

Snowball available through: http://stat.gamma.rug.nl/socnet.htm\#snowbal

UCINET and Netdraw by Borgatti, Everett and Freeman (2002) available through: http://www.analytictech.com/ucinet.htm 